\title{
Silicone Gel Mammary Prostheses in Albania and Breast-Feeding
}

Panajot Papa1, M.D. PhD.

Admir Jançe ${ }^{1}$, Ph.D.

Kristo Papa², M.D. PhD.

Prof. Asoc. Dr. Vera Ostreni ${ }^{1}$

${ }^{1}$ Faculty of Medical Science, Albanian University Tiran, Albania, ${ }^{2}$ Faculty of Medicine and Surgery, University of Verona, Italy Email: panajotpapa@gmail.com

Doi:10.5901/ajis.2015.v4n2s2p247

\begin{abstract}
We would define the security of silicone gel prostheses for the mother, the effects of an eventual contamination of maternal milk, if this condition is associate with elevate concentrations of silicone in the blood of their sons and if the silicon presence in correlate with immune pathology in the newborn. The aim of our study is to give an answer to these questions. From the December 2014 to December 2015, we were selected 20 women with ending pregnancy and mammary silicone gel prostheses. A commonly instruments were used to evaluate the concentration of antibodies, the silicone concentration was evaluated by spectroscopic analysis and devices silicone free were used. The tests results was elaborates statistically to verify the relation coefficient between the prostheses presence and the values of tests. The antibodies rate in all groups was compared and the difference wasn't significant. The evaluation of the concentration of inflammatory proteins in the newborn blood was performed at the start of the breast-feeding. The results were compared by $t$ Student test. Our results concord with the other present in literature. The search of haematic and antibody markers, helpful in the diagnosis of immune pathology, not put in evidence a peculiar relation cause-effect and it's absolute not specific. The same result is observe in the analysis of the newborns antibody rates in A group that in all tests haven't a statistic significance.
\end{abstract}

Keywords: Augmentation mammoplasty, mammary prostheses, silicone, breast-feeding.

\section{Introduction}

Augmentation mammoplasty was object of numerous controversies: could the mammary prostheses presence consider as risk factor for woman' pregnancy, lactation or fetus development? Could the silicone during the puerperium contaminates the milk and predisposes the newborn for immune pathology?

The clinical trials, present in literature, were born to give an answer to these questions, but often feel the effects of mistakes in the sampling. They resulting often without statistical significance or in contradiction.

The aim of our study is to give an answer to these questions. We would define the security of silicone gel prostheses for the mother, the effects of an eventual contamination of maternal milk, if this condition is associate with elevate concentrations of silicone in the blood of their sons and if the silicon presence in correlate with immune pathology in the newborn.

\section{Materials and Methods}

The study was conduct by the Department of Plastic, Reconstructive and Aesthetic Surgery Tirana (Albania). From the December 2014 to December 2015, we were selected 20 women with ending pregnancy and mammary silicone gel prostheses.

The exclusions criteria were: fibrocystic mastopathy, mastitis, immune pathology. The pregnancies secondary to assisted fecundation were excluded. implants.

The A group was flanked by a control group B that include 20 women with ending pregnancy without breast 
The A group show a mean age of $26 \pm 6$ years old. The mean time of implant permanence is $55 \pm 25$ months. $60 \%$ (12) of patients have the prostheses in subglandular plane and the $40 \%$ (8) submuscular plane. The mean pregnancy time is $39 \pm 2$ weeks and of breastfeed $28 \pm 2$ weeks. The B group has a mean age of $24 \pm 2$ years old, a pregnancy rate of $39 \pm 2$ weeks and the mean time of breastfeed is $23 \pm 6$ weeks.

At the pre-partus admission, we performed the evaluation of, Ig A,G and M classes and ANA, ENA antibody test in all patients.

The same laboratorial parameters were dosed in the sons of our patients at the star and at the end of the breastfeeding. We also performed the evaluation of silicone concentration in the whole blood in the mothers, in the sons and in maternal milk.

A commonly instruments were used to evaluate the concentration of antibodies, the silicone concentration was evaluated by spectroscopic analysis and devices silicone free were used.

The tests results was elaborates statistically to verify the relation coefficient between the prostheses presence and the values of tests.

\section{Results}

The silicone in the maternal blood resulted more concentrated in the patients of A group, the difference hasn't statistic significance. The antibodies rate in all groups was compared and the difference wasn't significant. The silicone concentration in the milk of both groups was super imposable. This condition points the absence of correlation between the mammary implant and the silicone rate in the milk. The evaluation of the concentration of inflammatory proteins in the newborn blood was performed at the start of the breast-feeding. The results were compared by $t$ Student test. The antibody rate was studied in the newborns of both groups in the same mode of the other tests.

\section{Discussion}

The silicon (Si) is one of the most concentrates elements on the earth crust and traces can be finding in the foods, makeup, in the drugs, dresses and in the hair of same person, too.

Numerous are the compounds presenting in nature based on Si but only for its crystalline form had been define the pathogenicity, because responsible of lung fibrosis and mesothelioma of pleura.

The organic form of Si, like silicone, is used to prepare prosthesis implant used in medicine.

The controversies on the security of mammary implants made in silicone gel had start from the 1985. The numerous case reports about patients with immune pathology that were considered as a consequence of augmentation mammoplasty brought the FDA to forbid the sale of silicone gel prosthesis from February 1992. In those period the augmentation mammoplasty by silicone gel implant had been reserve only to the patients received a mastectomy or volunteers enlisted in experimental trials. This phenomenon conducted to the start of numerous studies that affirmed or denied the relations between a local and/or systemic illness and the silicone gel prosthesis.

Actually the exact mode by the silicone could interact with the biologic tissues isn't completely known also the mode to act as a trigger for immune pathology. All prosthesis, independently from the other substances added to the silicone, induces a fibrous reaction from the periprosthetic tissues.

The cases of lymph-node biopsy reported in literature that put on evidence the presence of silicone depends by the phagocytosis process of the silicone molecules by macrophages and the successive transport of the material to the lymphatic stations.

The silicone caught from the macrophages can be derived from a premature prosthetic failure to the capsule formation or the bleeding of the gel through the prosthesis envelope.

The target of our studies is to define the relation between the silicon gel implants and the onset of immune pathology in the carrier and their sons, too. Our results concord with the other present in literature. The search of haematic and antibody markers, helpful in the diagnosis of immune pathology, not put in evidence a peculiar relation cause-effect and it's absolute not specific. The same result is observe in the analysis of the newborns antibody rates in A group that in all tests haven't a statistic significance. On the silicone concentration in maternal whole blood we observed great values in patients with prosthesis. This difference not appear liked to the silicone gel. Instead the silicone concentration dosed in the maternal milk and in the newborns blood is super imposable in all groups. The silicone is not sure the ideal material, but in our experience, today it's the best synthetic product available for the plastic surgeon, safety for female population. 


\section{References}

Spiera H, Kerr LD. Sclerodermia following silicone implantation: a cumulative experience of 11 cases. J Rheumatol. 1993; 20: 958-961.

Appleton BE, Lee P. The development of systemic sclerosis (scleroderma) following aubmentation mammoplasty. J rheumatol. 1993; 20: 1052-1054.

Bridges AJ, Conley C, Wang G, Burns D, Vasey F. A clinical and immunologic evaluation of woman with silicone breast implant and symptoms of rheumatic disease. Ann Intern med. 1993; 118: 929-936.

Teuber SS, Rowley MJ, Yoshida SH, Ansari A, Gershwin ME. Anti-collagen autoantibodies are foud in women with silicon breast implants. J auto-immun. 1993, 6: 367-377.

Yoshida SH, Chang CC, Teuber SS, Gershwin ME. Silicon and dilicone: Theorical and clinical implication of breast implants. Regul toxicol pharmacol. 1993; 17: 3-18.

Jordan ME, Blum RW. Should breast-feeding by women with silicone implants be recomanded? Arch pediatr adolesc. 1996; 150: 880881.

Angell M. Breas implants: protection or paternalism? N Engl J Med. 1992; 326: 1695-1696.

Teuber SS, Gershwin Me. Autoantibodies and clinical rheumatics in two children of woman with silicone gel breast implants. Int Arch Allergy Immunol. 1994; 103: 105-108.

Levine JJ, Ilowite NT. Sclerodermalike esophageal disease in children breast-fed by mothers with silicone breast implants. JAMA. 1994; 271: 213-216.

Berlin CH. Silicone breast implant and breast-feeding. Pediatrics. 1994; 94: 547-554.

Semple JL, Lugowski SJ, baines CJ, Smith DC, Mchugh A. Breast milk contamination and silicone implants: Preliminary result using silicon as proxy measurement for silicone. Plast Reconstr Surg. 1998; 528-533.

Levier RR, Harrison MC, Cook RR, Lane TH. What is silicone? Plast Reconstr Surg. 1993; 92: 163-167.

Lugowski SJ, Smith DC, Bonak H, Lugowski J, Peters W, Semple J. Analysis of silicon in human tissues with special references to silicon breast implants. J Trace Elements Med Biol. 2000; 14: 31-42.

Dunn KW, Hall PN, Khoo CT. Breast implant materials:sense and safety. Br J Plast Sur. 1992; 45: 315-321.

Cavic-Vlasak BA, Thompson M, Smith DC. Silicones ant their determination in biological matrices. Analyst. 1996; 121: 53R-63R.

Carlise EM. Silicon. Biochemistry of the essential ultratrace elements. E. Friden. New York and London, Plenum Press 1994: $257-291$.

Kessler DA. The basis of the FDA's decision on breast implants. N Engl J Med. 1992; 326: 1713-1715.

Roberts NB, Williams P. Silicone measurement in serum and urine by direct current plasma emission spectrometry. Clin Chem. 1990; 36: $1460-1465$

Exley C. Silicon in life. A bioinorganic solution to bioorganic essentiality. J Inorg Biochem 1998; 69: 139-144.

Thomsen JL, Christensen L, Neilsen M et al. Histologic changes and silicone concentration in human breast tissue surrounding silicone breast prostheses. Plast Reconstr Surg. 1990; 85: 38-41.

Barrett DM, O'Sullivan DL, Malizia AA, Reiman HM, Abell-Aleff PC. Particle shedding and migration from silicone genitourinary prosthetic device. J Urol. 1991; 146: 319-322.

Compton RA. Silicone manufacturing for long-term implants. J Long Term Effects Med Implants. 1997; 1: 29-54.

Cook RR. Epidemiology and silicone breast implants. J Clin Epidemiol. 1996; 48: 4: 519-525.

Peters W, Smith D, Lugowski S, Mchugh A, keresteci A, Baines C. Analysis of silicon levels in capsules of gel and saline breast implants and penile prostheses. Ann Plast Surg. 1995; 34: 6: 578-584

Hardt NS, Emery JA, Steinbach BG, Latorre G, Caffee H. Cellular transport of silicone from breast prostheses. Inter J Occup Med Toxixol. 1995; 4: 1: 127-134. 